
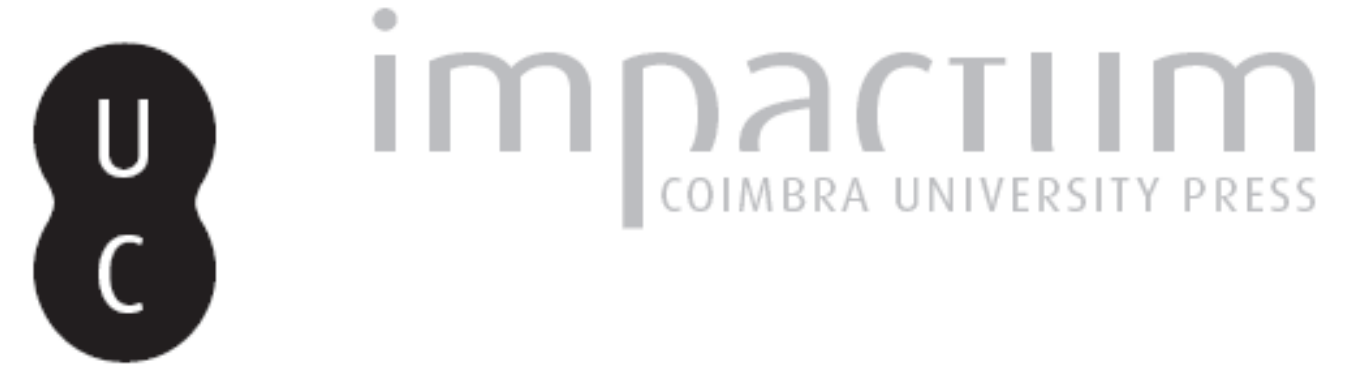

\title{
Lesión por desaceleración tras colisión frontal
}
Autor(es):
Hernando Lorenzo, A. E.; Gómez-Guillamón, F. García-Nieto; Anduaga, A. Menchaca

Publicado por: Imprensa da Universidade de Coimbra

URL persistente:

URI:http://hdl.handle.net/10316.2/33150

DOI:

DOI:http://dx.doi.org/10.14195/1647-8630_19_6

Accessed : $\quad$ 26-Apr-2023 15:29:28

A navegação consulta e descarregamento dos títulos inseridos nas Bibliotecas Digitais UC Digitalis, UC Pombalina e UC Impactum, pressupõem a aceitação plena e sem reservas dos Termos e Condições de Uso destas Bibliotecas Digitais, disponíveis em https://digitalis.uc.pt/pt-pt/termos.

Conforme exposto nos referidos Termos e Condições de Uso, o descarregamento de títulos de acesso restrito requer uma licença válida de autorização devendo o utilizador aceder ao(s) documento(s) a partir de um endereço de IP da instituição detentora da supramencionada licença.

Ao utilizador é apenas permitido o descarregamento para uso pessoal, pelo que o emprego do(s) título(s) descarregado(s) para outro fim, designadamente comercial, carece de autorização do respetivo autor ou editor da obra.

Na medida em que todas as obras da UC Digitalis se encontram protegidas pelo Código do Direito de Autor e Direitos Conexos e demais legislação aplicável, toda a cópia, parcial ou total, deste documento, nos casos em que é legalmente admitida, deverá conter ou fazer-se acompanhar por este aviso.

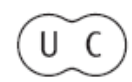




\section{Lesión por desaceleración tras colisión frontal}

A. E. Hernando Lorenzoํㅜㄹ. F. García-Nieto Gómez-Guillamón², A. Menchaca Anduaga

\section{Introducción}

A raíz de la investigación biomecánica de un accidente de tráfico, consistente en una colisión frontal entre un camión y un turismo, con el resultado de la muerte de los cuatro ocupantes del turismo, se revisan los mecanismos de lesión torácica por desaceleración, que presentaban, entre otras lesiones, los fallecidos.

\section{Descripción del caso}

Accidente de circulación ocurrido sobre las 06,45 horas del día 24 de agosto de 2008, en carretera Nacional, consistente en la colisión frontal angular derecha entre un camión Mercedes Benz modelo 1017 y un turismo Seat modelo Córdoba 1.9 TD, del que resultaron cuatro personas muertas, una persona herida grave y daños materiales de consideración en ambos vehículos.

Se refiere que a la llegada de la Fuerza Instructora al lugar del accidente, los vehículos ocupaban sus respectivas posiciones finales, en el interior del turismo Seat Córdoba se hallaban el conductor y los usuarios sin aparentes señales de vida, mientras que el conductor del camión Mercedes había sido rescatado del interior por unos usuarios desconocidos y era asistido de sus lesiones en el interior de una ambulancia, tras haber volcado el camión sobre su lateral izquierdo.

1 Médico; Especialista en Medicina Intensiva y Cardiología, Dpto. de Medicina Intensiva, Hospital Universitario "12 de Octubre", Madrid; Magister Universitario en Valoración del Daño Corporal

2 Médico; Especialista en Medicina Intensiva y en Anestesiología y Reanimación., Dpto. de Medicina Intensiva, Hospital Universitario "12 de Octubre", Madrid; Master Universitario en Pericia Sanitaria.

3 Enfermera; Directora de Enfermería del SUMMA 112 - Sistema de Emergencia de la Comunidad Autónoma de Madrid; Alumna del Curso de Master en Pericia Sanitaria 
Un testigo, en su manifestación circunstancial indicó "...que fue adelantado por el turismo Seat Córdoba, realizándolo su conductor a mucha velocidad..."

D. J. L. B., conductor del turismo, de 26 años de edad presentaba las siguientes lesiones: Erosiones faciales múltiples. Fractura hundimiento macizo facial y TCE abierto. Polifracturas torácicas, fracturas cerradas con luxación de miembro superior e inferior izquierdo.

En cavidad torácica: Se aprecian lesiones fracturarias en la parrilla costal derecha e izquierda. Los pulmones se encuentran multicontudidos con grandes zonas equimóticas contusas en su pared anterior tanto en el pulmón izquierdo como el derecho. En hemitórax derecho se aprecia varios litros de hemotórax. El pericardio se encuentra desgarrado con salida parcial del corazón de su habitáculo normal, existen desgarros de los grandes vasos a nivel de su inserción cardiaca. Tras disección de pericardio, se observan lesiones equimóticas en endocardio de ventrículo izquierdo.

En cavidad abdominal, importante hemoperitoneo que llega hasta fondo de saco de Douglas Hígado con numerosos desgarros por hiperflexión responsables del hemoperitoneo tan abundante de la cavidad. Resto de órganos sin interés.

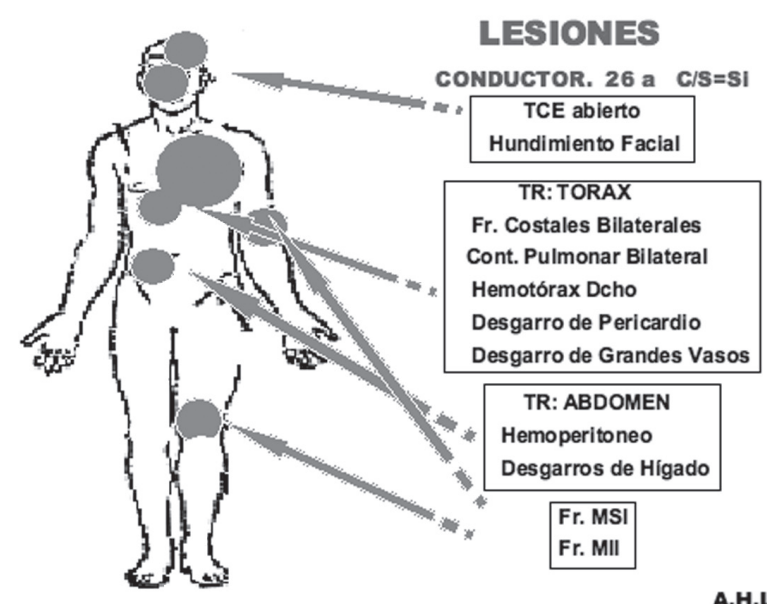

A.H.L.

D. J. L. V. R., ocupante del asiento delantero derecho, sufrió las siguientes lesiones: En cara, en región fronto-parietal central, amplia herida contusa por donde se aprecia la salida de masa encefálica y se aprecia hemorragia encefálica importante. Herida contusa en región interciliar. A la palpación, fractura polifragmentaria de bóveda craneal, y de todo el macizo facial con importante crepitación entre los fragmentos libres. Otorragia bilateral con salida de masa encefálica indicativo de la existencia de una fractura a nivel 
de los huesos de la base craneal. Múltiples escoriaciones y heridas contusas e incisas en toda la cara más abundantes en el lado izquierdo.

En tronco, en el costado derecho amplia herida contusa con gran atrición de los tejidos subyacentes. Amplia herida contusa en región torácica en donde se halla enclavado un trozo de material plástico procedente del vehículo, de forma rectangular y de color negro, que podría tratarse de la tapa de la radio o de algún otro elemento del salpicadero. En todo el plano toraco-abdominal anterior numerosas heridas contusas, excoriaciones y quemadura por fricción.

En extremidades superiores: Excoriación longitudinal en hombro derecho, amplias excoriaciones a lo largo del brazo y antebrazo, y herida contusa en dorso de la mano izquierda. En la extremidad derecha fractura cerrada a nivel del tercio distal de cubito y radio con deformidad manifiesta de la zona.

En extremidades inferiores: Erosión lineal en cara posterior del muslo derecho. Fractura de ambos fémures con gran deformidad, crepitación y movilidad anormal. Fractura de tibia izquierda. Herida contusa en dorso del pie izquierdo.

\section{Examen interno}

La palpación y la inspección a través de la amplia herida contusa del tórax tras retirar el objeto extraño que la ha causado, pone de relieve la existencia de numerosas fracturas costales la afectación importante de pulmones y corazón y la existencia de hemorragia interna.

A nivel abdominal a la palpación se aprecia fluctuación por la existencia de líquido libre, consecuencia de lesiones viscerales que han dado lugar a hemorragias internas, por todo ello no se considera necesario proceder a su apertura.

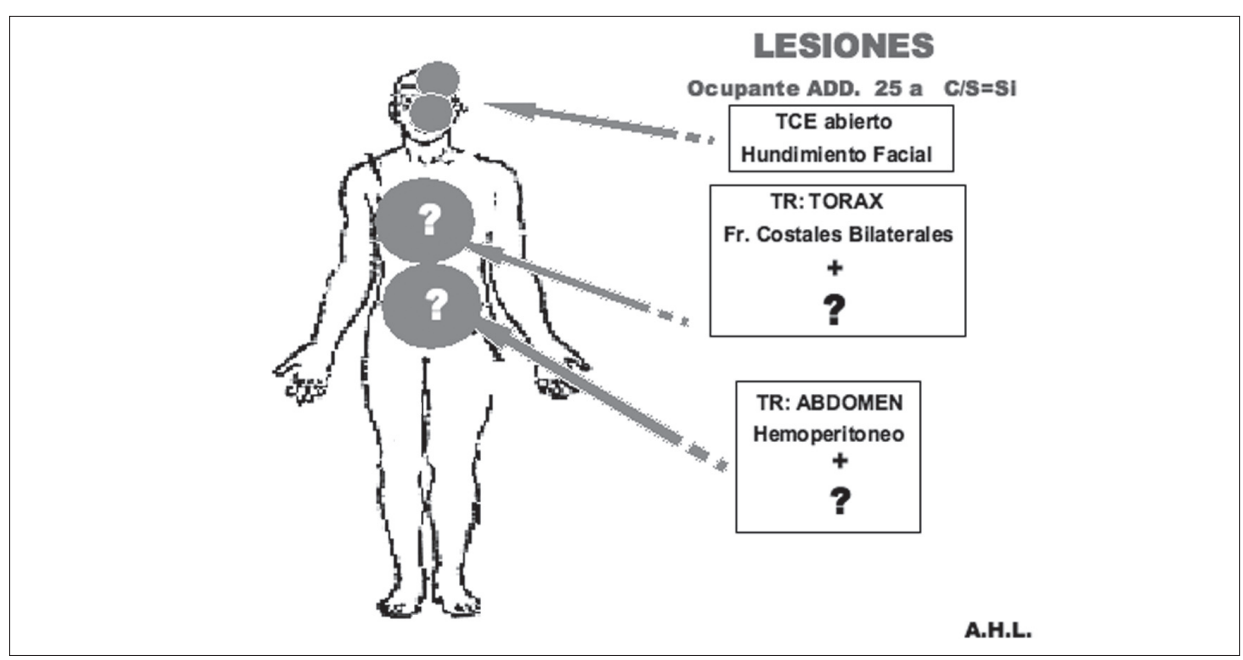




\section{Consideraciones medico-forenses}

El cuerpo del fallecido ha sufrido un fuerte impacto frontal con graves lesiones a nivel craneal y toraco-abdominal. La presencia de múltiples cristales y restos de materiales plásticos del salpicadero, confirma la posición que ocupaba en el vehículo, usuario delantero derecho. También esta posición explica la fractura de las extremidades inferiores.

\section{Conclusiones medico-forenses}

Que J. L. V. R. murió de forma violenta, que la etiología de la muerte fue la accidental (accidente de tráfico), que la causa inmediata fue la destrucción de centros vitales, siendo la causa fundamenta un politraumatismo con traumatismo craneoencefálico abierto y traumatismo toraco-abdominal.

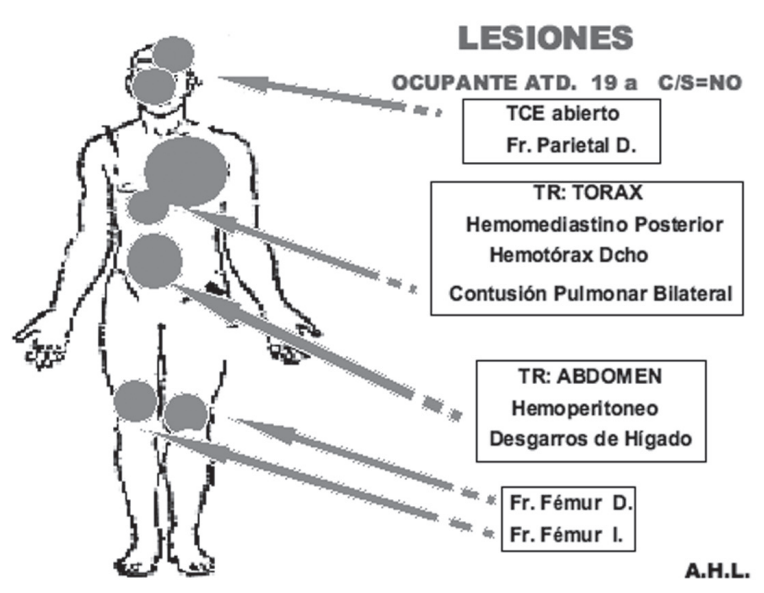

D. Y. D. M., ocupante del asiento trasero derecho, de 24 años de edad, sufrió las siguientes lesiones:

En cara, en región parietal derecha, amplia herida contusa en scalp con un gran colgajo en forma semicircular por donde se aprecia que existe una fractura con depresión del fragmento en bóveda craneal y hemorragia encefálica importante. Múltiples escoriaciones y heridas contusas e incisas en toda la cara más abundantes en región central de frente, nariz y boca. En cavidad craneal existe fractura de bóveda craneal y hemorragia encefálica.

En cuello: Dos escoriaciones de unos dos centímetros y paralelas entre sí en cara lateral derecha.

En tronco: En todo el plano toraco-abdominal anterior, excoriaciones y quemaduras por fricción. No lesiones en la espalda. Tras la disección de partes blandas y retirar el peto esterno-costal donde no existen lesiones osteomuscu- 
lares, quedan al descubierto las vísceras de estas cavidades donde se aprecia: hemotórax derecho, hemomediastino posterior, contusiones hemorrágicas en todo el pulmón derecho y en el lóbulo superior del izquierdo. Hemoperitoneo. Desgarros en cara superior e inferior del hígado.

En extremidades inferiores: Excoriaciones en cara anterior y lateral interna el tercio distal del muslo derecho con fractura del fémur a este nivel. Herida contusa en cara anterior de pierna derecha. Fractura cerrada de tercio distal de fémur izquierdo.

\section{Consideraciones medico-forenses}

El cuerpo del fallecido ha sufrido un fuerte impacto frontal con graves lesiones a nivel craneal y toraco-abdominal predominantemente en el hemicuerpo derecho, incompatibles con la vida y que se explican por la posición que tenía en el vehículo.

\section{Conclusiones medico-forenses}

Y. D. M. murió de forma violenta, que la etiología médico-legal de la misma fue la accidental (accidente de tráfico), siendo la causa inmediata un shock hipovolémico post-hemorrágico, siendo la causa fundamenta un politraumatismo con traumatismo craneoencefálico abierto y traumatismo toraco-abdominal.

D. J. M. V. G. ocupante del asiento trasero izquierdo, de 26 años de edad, sufrió las siguientes lesiones: erosiones faciales múltiples. TCE abierto. Pérdida de órbita derecha. Polifracturas torácicas de miembros superiores e inferiores abiertas con luxación de fragmentos.

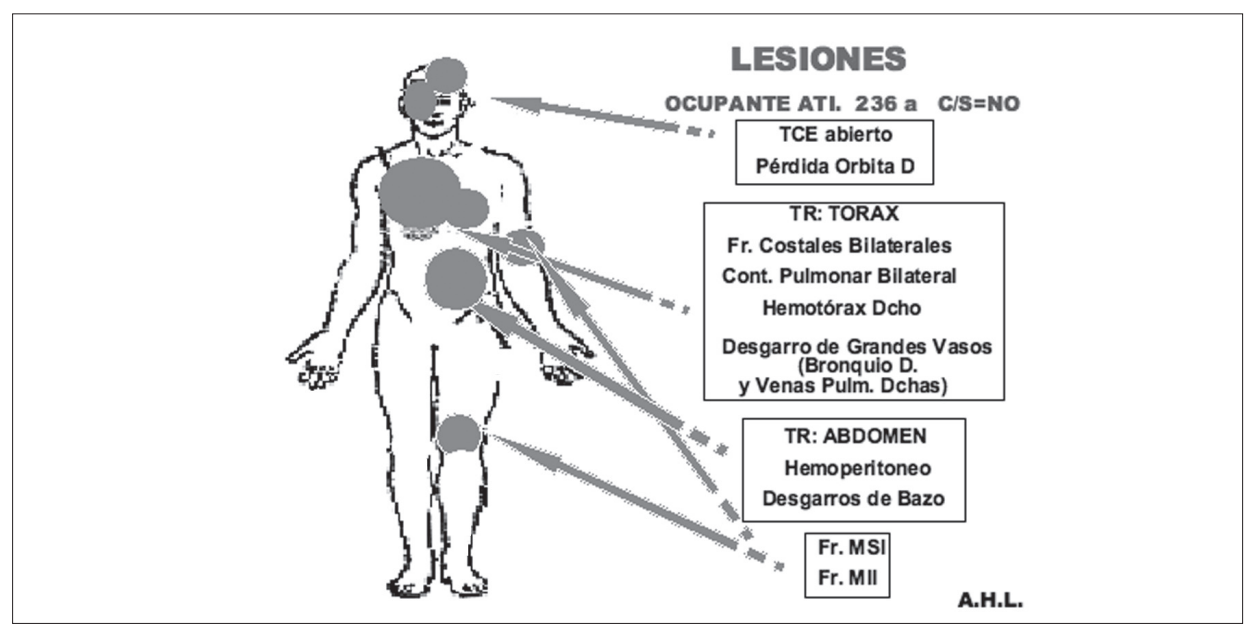


En cavidad craneal, lesiones traumáticas de TCE abierta a la inspección y palpación; se decide respetar su apertura.

Cavidad torácica: Se aprecian lesiones fructuarias en la parrilla costal derecha e izquierda. Los pulmones se encuentran multicontundidos con grandes zonas equimóticas contusas en su pared anterior tanto en el pulmón izquierdo como en el derecho. En hemitórax derecho se aprecia varios litros de hemotórax. Existen desgarros de los grandes vasos a nivel de su inserción cardiaca, encontrándose a este nivel: bronquio y venas pulmonares derechas con grades desgarros. El corazón tras disección de pericardio muestra lesiones equimóticas en endocardio de ventrículo izquierdo.

En cavidad abdominal se aprecia un importante hemoperitoneo que llega hasta fondo de saco de Douglas. Se observa desgarros de bazo responsables del hemoperitoneo. Resto de vísceras sin interés.

\section{Valoración medico-legal}

Se ha puesto de manifiesta la existencia de un traumatismo torácico cerrado que ha producido multicontusiones pulmonares y desgarro de grandes vasos y pulmón derecho. Por otro lado, otra lesión importante se encuentra a nivel craneal con fractura abierta craneal y pérdida de órbita derecha. Se ha encontrado en abdomen un importante hemoperitoneo como consecuencia de desgarros de bazo por hiperflexión del órgano. Por último, se ha evidenciado fracturas cerradas con luxación e miembro superior e inferior izquierdo. Las lesiones son compatibles con accidente de tráfico.

\section{Conclusiones}

Naturaleza de la muerte, violenta, siendo la causa y mecanismo de la misma, parada cardio-respiratoria. Traumatismo torácico cerrado. TCE abierto. Hemorragia interna aguda, siendo la etiología de la misma, accidental derivado de tránsito rodado.

\section{Investigación del accidente}

Tras visita realizada a la zona del accidente y entrevista con el propietario del camión siniestrado y con el operario de la grúa que retiró el turismo siniestrado, se obtuvo por parte del perito médico la siguiente información:

$\mathrm{El}$ accidente se produjo sobre las 06,00 horas de la mañana, cuando el automóvil conducido por cuatro jóvenes, adelantó a un coche conducido por un bombero (testigo) y a un coche conducido por un Guardia Civil que iba 
a trabajar, invadiendo el carril contrario en una curva que es punto negro, produciéndose la colisión frontal contra el camión, el cual volcó sobre su lado izquierdo a consecuencia del impacto.

El conductor del camión le declaró que iba a unos 30-40 Km/h, con el cinturón de seguridad y que vió venir el coche, quedando aturdido tras la colisión, saliendo por arriba (ventanilla de puerta derecha) tras no poder abrir la puerta de su lado. El conductor había realizado una maniobra evasiva dirigiéndose hacia la derecha, hacia el arcén, al ver venir el coche.

La Guardia Civil tras recoger el disco tacógrafo del camión, comentó que marcaba alrededor de $30 \mathrm{Km} / \mathrm{h}$ ). -El propietario del camión me comenta que el conductor llevaba solamente 30 minutos trabajando-).

En la zona donde se produjo el siniestro, se había producido otro accidente recientemente (en efecto en la zona del accidente se observan flores sobre la banda bionda que me comenta corresponden a otro accidente previo al ocurrido la madrugada del 24 de agosto).

(Recortes de prensa: Lavozdigital.es - local - Ciudadanos, en efecto refiere que: "El accidente de Vejer ocurrió en un punto negro con escasa señalización”).

El día del accidente no había niebla, el camión circulaba prácticamente vacío; se trata de un camión comprado en subasta del ejército alemán, tratándose de un camión usado con tracción $4 \times 4$ que transportaba una cisterna con agua, estando la cisterna prácticamente vacía.

El camión siniestrado presentaba entre otros los siguientes desperfectos:

El neumático derecho delantero reventado, rota la caja de cambios por su parte media, doblada la cabina y doblado el cardan, rota la caja $4 \times 4$, observándose restos de sangre en la parte frontal a la altura del parachoques, que correspondería a alguno de los ocupantes del turismo. En la puerta derecha del camión se observa sangre correspondiente al conductor del camión quien salió por la ventanilla de ese lado y que al parecer sufrió un TCE leve con conmoción cerebral, y una fractura abierta en mano izquierda de la que ha tenido que ser intervenido en dos ocasiones (desconociendo por mi parte si existe alguna lesión adicional).

La cisterna presenta también deformaciones en su lado izquierdo, correspondientes al fuerte impacto al volcar, así como deformaciones en su parte delantera.

Dadas las características del camión y su tara y observadas las deformaciones, tanto del camión como del turismo siniestrado se trata de una colisión frontal a alta velocidad con gran disipación de energía.

La zona del accidente, se trata de una carretera nacional con curva hacia la izquierda según el sentido de circulación del camión. La curva tiene señalización horizontal con línea continua y al camión le afecta señal de límite de circulación a $60 \mathrm{Km} / \mathrm{h}$. 
En la zona del accidente al parecer había tras el mismo huellas de derrape del turismo.

Entre las causas del accidente podría haber habido un despiste del conductor del turismo, creyendo que continuaba por la autovía, circulando por tanto por el carril izquierdo de la carretera nacional, una vez se había terminado la autovía.

Esta explicación no parece factible, ya que la distancia que hay entre la finalización de la autovía y el punto del accidente es superior a dos kilómetros, por lo que no parece posible que no se hubiesen encontrado con tráfico de frente antes de producirse la colisión.

De cualquier forma, al automóvil y en la zona previa al impacto, estando ya en la carretera nacional, le afectaban señales de $80 \mathrm{Km} / \mathrm{h}$, seguida de otra con limitación a $60 \mathrm{Km} / \mathrm{h}$ y de otras a continuación con prohibido adelantar y cruce con prioridad, existiendo como señalización horizontal línea doble continua.

En la zona del impacto había restos y vestigios del accidente de los cuales estaban restos de la matrícula delantera del camión, un cenicero del turismo, un perno de la parte delantera del camión (parachoques), etc.

El turismo presentaba grandes deformaciones correspondientes a un impacto frontal excéntrico angular que afectaba sobre todo a la parte delantera derecha, hasta sobrepasar la mitad del frontal del turismo. El eje delantero derecho tenía una desviación hacia atrás de unos $50 \mathrm{cms}$. Había intrusión en el habitáculo. El volante estaba torcido y había retroceso de la zona de pedales en el habitáculo. El volante estaba torcido en sentido horario (más cerca del conductor la parte derecha del volante), y deformado en su circunferencia.

Llamaba la atención la marcada deformación de los asientos delanteros, que están doblados hacia delante en la zona del respaldo, existiendo sangre en ambos respaldos. Estas deformaciones marcadas se deben al empuje producido hacia delante por los dos ocupantes de los dos asientos traseros, al no quedar retenidos por cinturón de seguridad.

Los dos cinturones de seguridad delanteros estaban cortados tras haberse producido el rescate de conductor y acompañante, por parte de los bomberos (el automóvil comenzó a incendiarse -se trata de un Seat Córdoba diésel).

Los dos cinturones traseros laterales no habían sido utilizados, estando el derecho atrapado por detrás del respaldo del asiento, y el izquierdo en posición de reposo.

Se observa masa encefálica en la parte interior de la ventanilla trasera izquierda.

Las ruedas del turismo presentan los neumáticos con dibujo conservado aparentemente y la rueda delantera derecha está atrapada con el guardabarros.

Las puertas del lado derecho han sido retiradas durante el rescate. Las puertas del lado izquierdo permiten su apertura aunque están relativamente encajadas. 
El cuenta kilómetros del turismo tiene la aguja del velocímetro detenida en $110 \mathrm{Km} / \mathrm{h}$. El turismo no dispone de airbags.

El lateral izquierdo muestra raspaduras que podrían deberse a golpe contra la bionda, previamente a meterse debajo de la esquina delantera derecha del camión, haciéndole volcar hacia su izquierda.
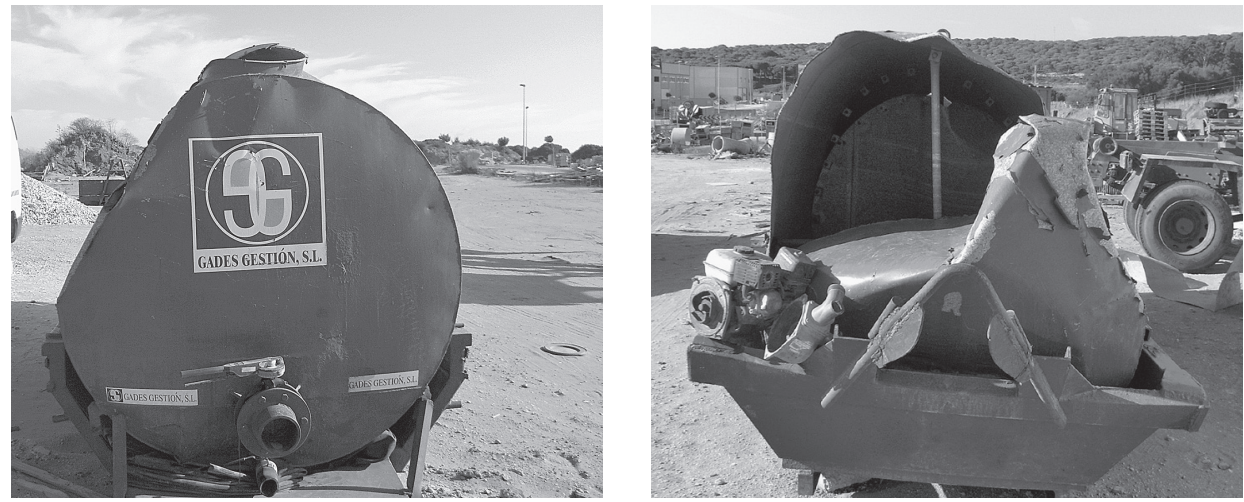

Deformaciones en la cisterna del camión tras el vuelco hacia la izquierda

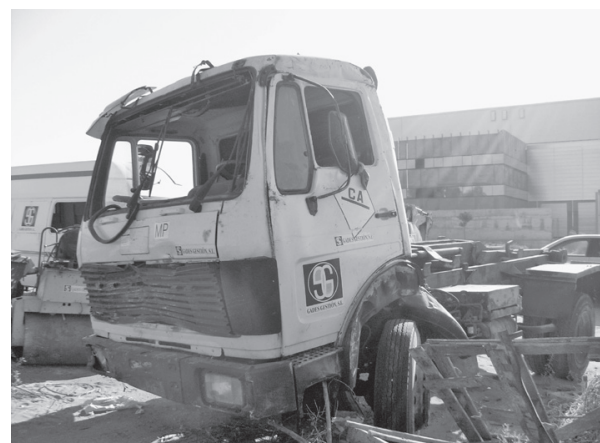

Deformaciones en el frontal del camión por el impacto

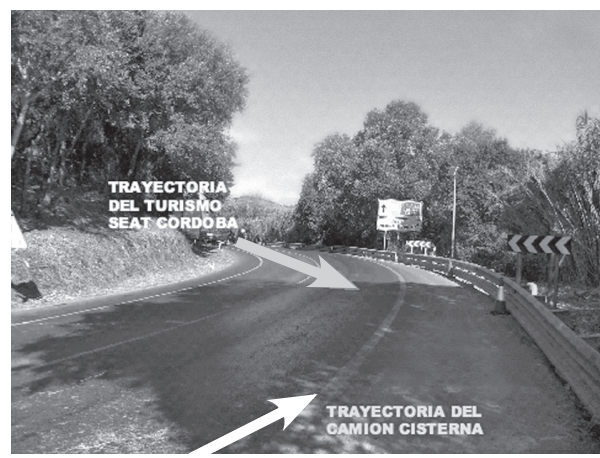

Trayectorias seguidas por el turismo Seat Córdoba y el camión

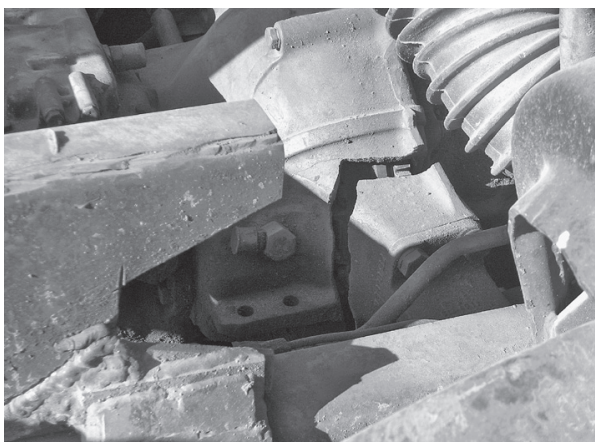

Daños en la estructura inferior del camión por transmisión de fuerza

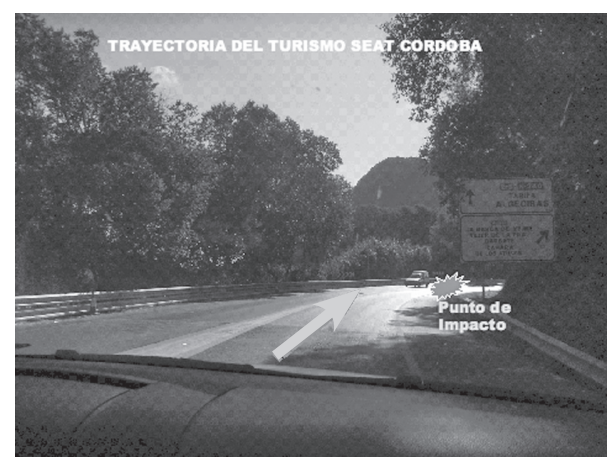

Revista Portuguesa do Dano Corporal (19), 2009

[p. 121-146] 

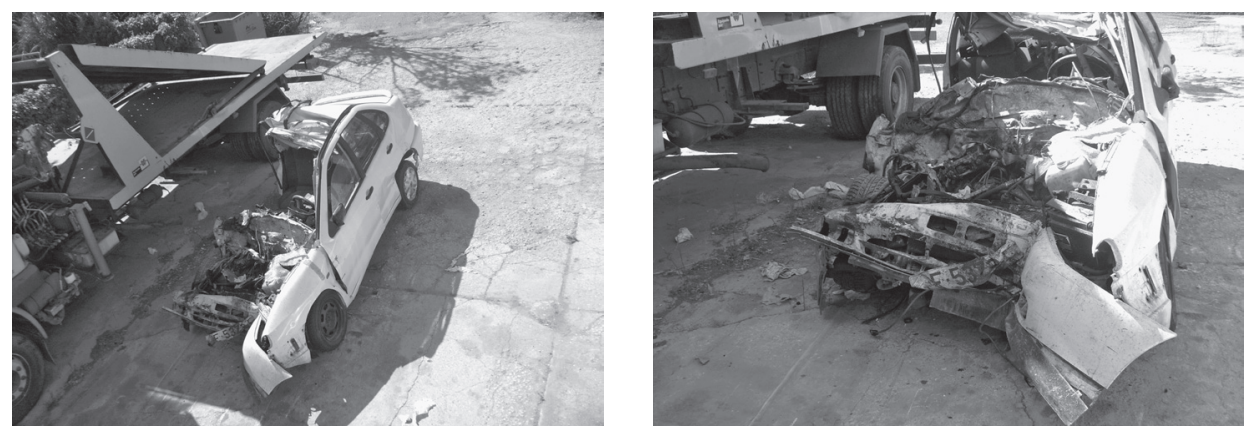

Desperfectos y deformaciones en el turismo Seat Córdoba
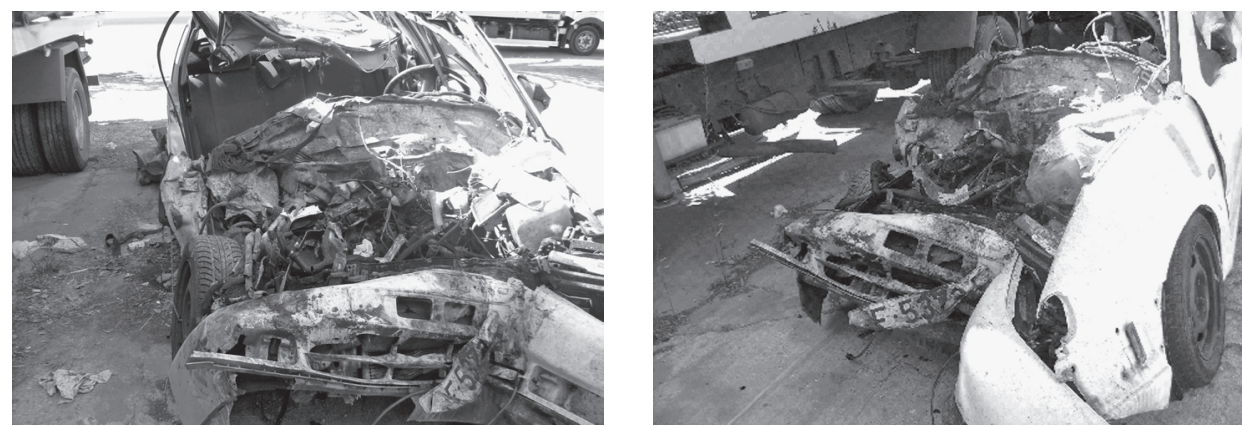

Desperfectos y deformaciones en el turismo Seat Córdoba

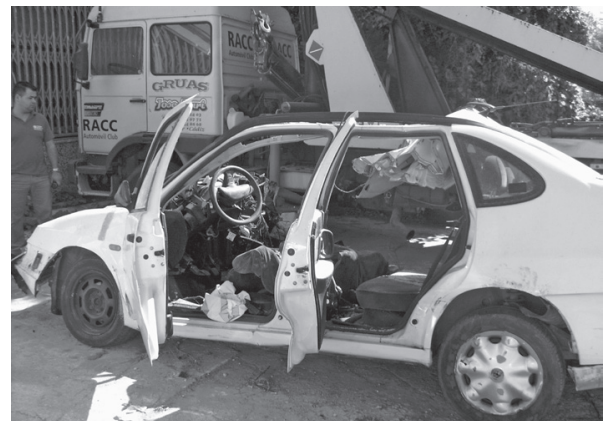

Deformación en el volante de la dirección

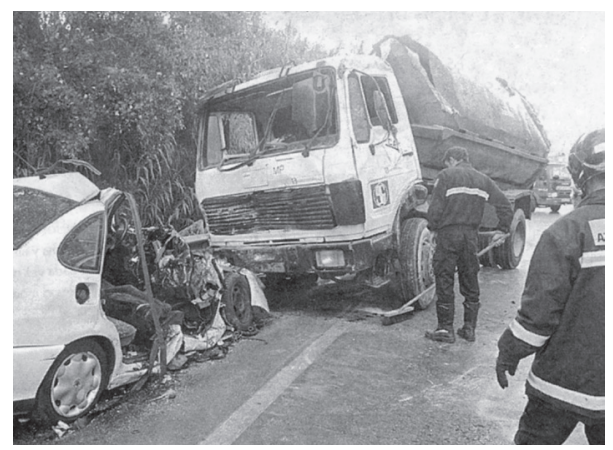

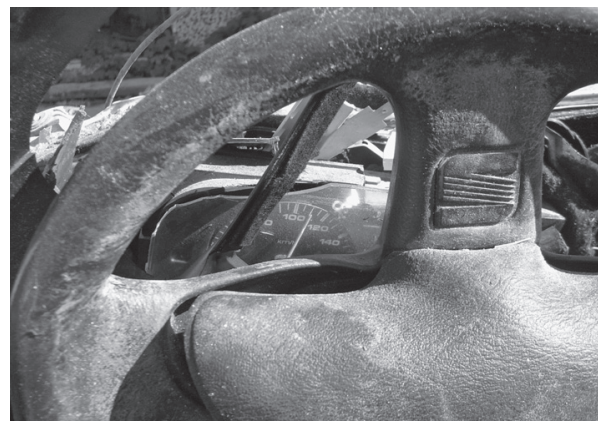

Velocímetro con la aguja señalando $110 \mathrm{kms} / \mathrm{h}$

Colision frontal camion cisterna

- Seat Córdoba 


\section{Discusión y comentarios}

Se trata de un accidente de tráfico en el que fallecieron cuatro jóvenes, tras colisionar frontalmente con gran violencia el turismo en el que viajaban, contra un camión. Los dos ocupantes del asiento delantero utilizaban cinturón de seguridad y los del asiento trasero no lo utilizaban.

De forma aproximada (y con las reservas correspondientes), se puede considerar que el cambio de velocidad del turismo /delta-v) en el momento del impacto fue superior a $100 \mathrm{kms} / \mathrm{h}$., lo que implicó la acción de grandes fuerzas de desaceleración sobre los ocupantes del turismo.

Deben tenerse en cuenta las siguientes circunstancias: La gran diferencia de pesos entre los dos vehículos involucrados en el accidente (incompatibilidad), la dirección principal de fuerza que afectó a los ocupantes del turismo, de delante hacia atrás, enfrentándose a la tendencia de sus cuerpos a desplazarse hacia delante; el uso o no de cinturón de seguridad por parte de los ocupantes; etc.

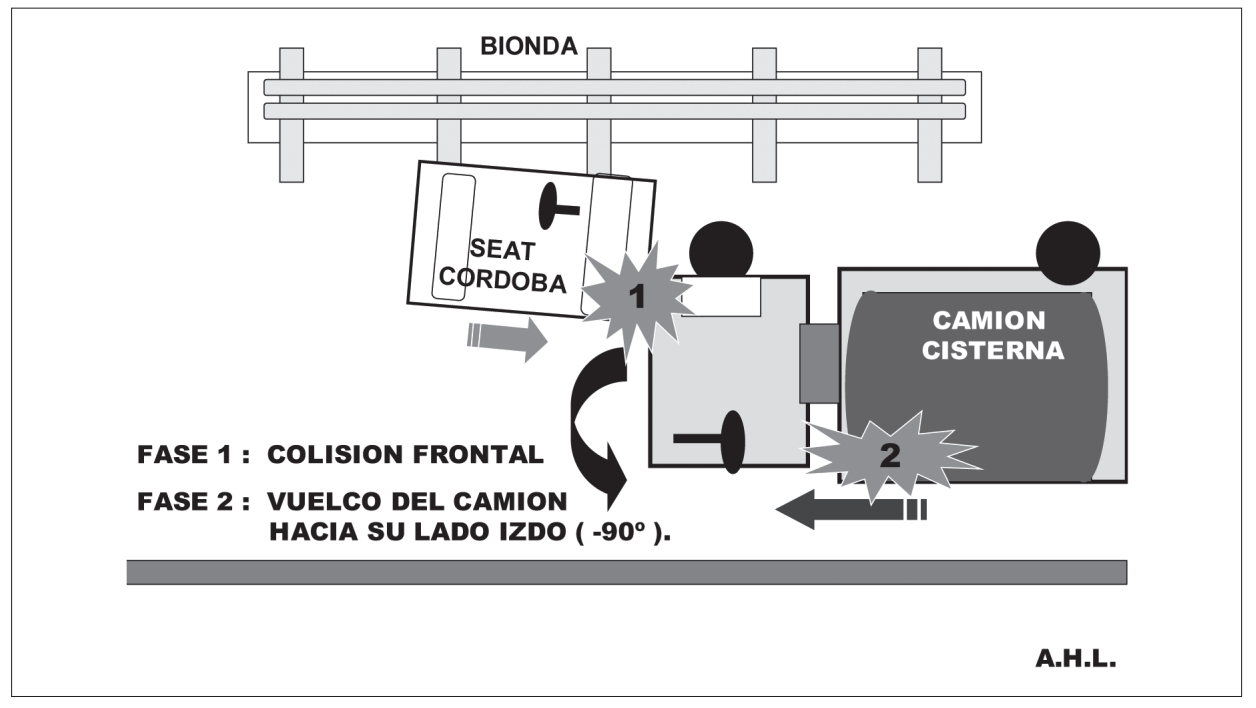

Los mecanismos por los que se producen lesiones en colisiones tras accidentes de tráfico son: a.- contacto - el cuerpo de los ocupantes contacta con estructuras del interior del turismo y/o contra otros ocupantes-, b.- intrusión -se producen deformaciones en el turismo por fuerzas externas, que hacen que las estructuras del vehículo se proyecten hacia el interior, reduciendo el espacio del habitáculo del vehículo- y c.- desaceleración, producida por un cambio de velocidad muy rápido, y de intensidad variable. (En el accidente que comentamos, habrían existido los tres mecanismos). 
Los ocupantes del turismo tenían lesiones cráneoencefálicas, toracoabdominales y en miembros, que determinaron su muerte inmediata «in situ». La discusión que sigue, versará exclusivamente sobre las lesiones torácicas por desaceleración.

Swank. G. y cols., "Deceleration Thoracic Injury", "Lesión Torácica por Desaceleración”, J. Trauma, 2001, Vol. 51: 970-974, refieren que entre las cinco lesiones principales torácicas por deceleración (contusión miocárdica, rotura traumática de aorta, fractura esternal, volet torácico y rotura traqueobronquial), las lesiones coexistentes son llamativamente raras.

Los autores revisaron las historias clínicas de todos los pacientes con diagnósticos finales de las lesiones mencionadas anteriormente tratadas en el Centro Médico de la Universidad de New Jersey en Newark, en los diez años precedentes a 1997.

Entre 142 pacientes, todas víctimas de accidentes de tráfico hubo 38 contusiones miocárdicas, 36 roturas traumáticas de aorta, 33 fracturas esternales, 28 volets torácicos y 7 roturas traqueobronquiales. Hubo seis lesiones coexistentes $(3,5 \%)$.

Las lesiones torácicas por deceleración se producen cuando un individuo se mueve hacia delante y se detiene repentinamente, golpeando con alguna parte del tórax con algún obstáculo que está fijo o se mueve a una velocidad mucho menor.

Los accidentes de tráfico son la causa más frecuente y los ocupantes de los asientos delanteros son los más vulnerables. Las caídas desde altura son otras causas de ese tipo de lesiones.

Las lesiones principales a menudo con riesgo vital, incluyen rotura traumática de aorta, rotura traqueo-bronquial, contusión miocárdica, fractura esternal y volet torácico. Algo sorprendente es la observación de que raramente se ven cualquiera de estas lesiones combinadas en el mismo paciente. Por ejemplo un choque frontal entre automóviles y conductores comparables, produce una fractura esternal sufrida por un conductor y una rotura traumática de aorta por el otro.

Los autores mantienen la hipótesis de que esas lesiones torácicas por deceleración, pueden producirse por combinación y que los pacientes con ellas raramente llegan vivos al hospital y que si lo hacen, el pronóstico es sombrío.

La infrecuente observación de lesiones asociadas, puede deberse a que dichas lesiones no se reconocen, debido a que la víctima muere en la zona del accidente o poco tiempo después de la llegada al hospital, y no se realiza la autopsia. Si se observan lesiones coexistentes, el pronóstico es malo, ya que en este estudio se observó una mortalidad del $67 \%$. Si existía asociación de tres lesiones torácicas por deceleración, el pronóstico era incluso peor, mostrando una mortalidad del $100 \%$. 
La rotura traqueo-bronquial producida por lesión por deceleración en tórax, se explica por el mecanismo más frecuentemente citado que es la compresión del esternón contra la columna que desplaza hasta el pulmón lateralmente.

Al ocurrir esto, la tráquea se desgarra cerca de la carina y cualquiera o ambos de los bronquios principales pueden también desgarrarse. Por esta razón el $80 \%$ de tales lesiones se producen en los 2,5 cms. próximos a la carina. Estas lesiones son también raras, o al menos se encuentran raramente, ya que hasta el $82 \%$ de pacientes con tales lesiones, mueren antes de llegar al hospital.

Los autores vieron una incidencia de 0,7 por año en un Centro de Trauma de Nivel I y otros refieren incidencias similares, que varían de 0,3 a 1 caso por año.

En lo que se refiere a la lesión de aorta torácica, las otras lesiones torácicas son vistas raramente en un superviviente, pero ésto no significa que no se produzcan. Ya que más del $85 \%$ de pacientes con rotura traumática de aorta mueren "in situ", sólo unos pocos reciben la atención del médico con posibilidad de estudios complementarios en el hospital.

La rotura traumática de aorta en un superviviente es más que probable que sea una lesión torácica aislada y la literatura apoya este postulado. En un análisis de 137 artículos publicados entre 1976 y 1997 sobre el tema de Trauma Cerrado de Aorta Torácica, Nagy y cols. (J. Trauma, 2000; 48: 11281143), concluían que "parece haber una asociación negativa con fracturas del esqueleto torácico”.

En su revisión de 182 pacientes con rotura traumática de aorta tratados en diez Centros Quirúrgicos Cardiovasculares en Francia, Atou y cols. (Ann. Thorac. Surg. 2000; 69: 70-73), no listaban ninguna de las otras cuatro lesiones torácicas entre las muchas lesiones asociadas sufridas por su población de pacientes.

Hunt y cols., del Registro de Trauma de Carolina del Norte, refirieron 144 pacientes con rotura traumática de aorta tratados en ocho Centros de Trauma de Nivel I-II en un periodo de siete años. Hubo 9 pacientes con fracturas esternales y 10 pacientes con "volet torácico" (6\% y 7\% respectivamente).

En un estudio de lesión aórtica en accidentes de tráfico, Williams y cols. (Ann. Thorac. Surg. 1994; 57: 726-730), encontraron 105 en 90 víctimas (15 tenían lesiones aórticas múltiples) en un periodo de 5 años en la Oficina del Forense del Condado de Erie (Nueva York). Se encontraron fracturas costales múltiples en el $78 \%$ y fractura esternal en el 28\%. Casi todos los pacientes (94\%) habían muerto en la primera hora tras la lesión.

Las lesiones cardíacas por traumatismo cerrado están entre las causas principales de muerte tras accidentes de tráfico (Krasna MJ, Flancbaum L. 
"Blunt cardiac trauma: clinical manifestations and Management", Semin Thorac Cardiovasc Surg 1992 ;4(3):195-202). La lesion en corazón está presente en alrededor del 20\% de los muertos en accidentes de tráfico (Fitzgerald M, Spencer J, Johnson F, Marasco S, Atkin C, Kossmann T. "Definitive management of acute cardiac tamponade secondary to blunt trauma”, Emerg Med Australas 2005;17(5-6):494-9. Las lesiones cardíacas estaban presentes en un 16\% de los pacientes en la serie de Glinz et al. (Glinz W, Turina M. Blunt heart injuries. Langenbecks Arch Chir 1986;369:129-38) de los pacientes que habían sufrido traumatismo torácico cerradoy el $25 \%$ de estos casos no tenían fracturas costales concomitants. Las roturas de cámaras cardíacas están presentes en autopsia en 36-65\% de muertos por traumatismo cardíaco cerrado, mientras que en las series clínicas, sólo se refiere en un $0.3-0.9 \%$ de casos, y es un hallazgo infrecuente. Las lesiones cardíacas pueden afectar a diferentes estructuras:: pericardio, miocardio, arterias y venas coronarias, cuerdas, músculos papilares y válvulas y grandes vasos.

La rotura cardíaca es una lesión torácica de gran riesgo vital inmediato, dado el compromiso hemodinámico que produce. Se da en grandes traumatismos torácicos (traumatismos torácicos abiertos y heridas por arma de fuego o arma blanca, así como en traumatismos torácicos cerrados de gran energía). La rotura cardíaca produce un taponamiento cardíaco masivo al llenarse el saco pericárdico con la sangre procedente de las cavidades cardíacas. Si es una rotura abierta, origina un shock hipovolémico con hemotórax masivo, sin taponamiento cardíaco, y el pronóstico es fatal.

En España, la causa más frecuente de traumatismo cardíaco es el secundario al traumatismo torácico sufrido tras un accidente de tráfico, bien por contusión directa en la cara anterior del tórax o por mecanismo de aceleración-deceleración con afectación cardíaca y ocasionalmente vascular. Sin embargo, en los últimos años se ha observado, posiblemente en relación con la utilización de mecanismos pasivos de seguridad como el "airbag" en los automóviles, que el índice de lesiones secundarias a traumatismo torácico directo ha disminuido de manera considerable.

La American Association for the Surgery of Trauma (AAST) y en concreto su comité Organ Injury Scaling (OIS) desarrolló en 1994 una escala con seis niveles para objetivar la severidad del traumatismo cardíaco, con el fin de describir uniformemente las diferentes lesiones, realizar una gradación respecto al nivel de afectación cardíaca y evaluar su pronóstico.

La incidencia de daño cardíaco en el traumatismo torácico cerrado se ha cifrado en torno al 10-16\%. La etiología más frecuente del traumatismo cardíaco cerrado en nuestro medio es el accidente de tráfico, pero también puede ser una consecuencia de caídas de altura, golpes recibidos en peleas o por la práctica de deportes de riesgo. 
Los principales mecanismos de afectación del corazón durante un accidente de tráfico son la compresión brusca del mismo entre el esternón y la columna vertebral y el movimiento de aceleración-deceleración, que es el origen de múltiples lesiones, tanto cardíacas como de los grandes vasos del tórax.

Por lo general afecta a las cámaras de baja presión - cavidades derechas (aurícula y ventrículo derechos), y por su mayor proximidad al esternón, la pared libre de ventrículo derecho es la más propensa a sufrir una contusión cardíaca (Chiu WC, D'Amelio LF, Hammond JS. "Sternal fractures in blunt chest trauma: a practical algorithm for management”, Am J Emerg Med 1997; 15: 252-255), principalmente cuando la contusión es frontal-como en el caso que comentamos-. Sin embargo, entre los que llegan vivos al hospital, la auricular derecha es la cámara afectada con mayor frecuencia. En hasta el 30\% da casos, la rotura afecta a mas de una cámara.

En muchas ocasiones se observan lesiones valvulares sin afectación de la pared libre y, aunque no son muy frecuentes, se han descrito casos de grave disfunción de la válvula tricuspídea o mitral. El traumatismo afecta generalmente al aparato subvalvular y lesiona las cuerdas tendinosas y los músculos papilares; estas lesiones se manifiestan coincidiendo con la diástole, cuando el ventrículo se encuentra distendido. La válvula aórtica se lesiona por rotura directa del anillo o por afectación de la aorta ascendente. También pueden objetivarse fístulas entre cavidades

Según Perchinsky, M.J., W.B. Long, and J.G. Hill, "Blunt Cardiac Rupture”, Arch Surg, 1995. 130: p. 852-857, el traumatismo cardíaco cerrado, en su mayoría producido en el contexto de accidentes de tráfico, puede causar rotura miocárdica como resultado de la compresión cardíaca entre el esternón y la columna, por impacto directo (traumatismo esternal, o por lesión por desaceleración, o por una combinación de ellas.

Puede producir rotura de los músculos papilares, rotura de la pared libre cardíaca o del tabique interventricular. Las cámaras cardiacas afectadas, en órden decreciente de frecuencia, son el ventrículo derecho, el ventrículo izquierdo, la aurícula derecha y la aurícula izquierda.

El traumatismo cerrado sobre el pericardio desarrolla, por regla general, poca repercusión clínica, ya que muchos desgarros que se producen en esta estructura pasan desapercibidos, aunque ocasionalmente puede originar complicaciones como derrames pericárdicos con o sin taponamiento cardíaco, bien de forma aguda o subaguda (José Ramón Echevarría J R, San Román A. "Evaluación y tratamiento de los traumatismos cardíacos", Rev Esp Cardiol 2000; 53: 727 - 735 .

En ocasiones, la presencia de líquido se cronifica, originando con el tiempo una pericarditis constrictiva que en algunos casos ha hecho necesaria la práctica de una pericardiectomía. Si el desgarro pericárdico es muy amplio, 
el corazón puede desplazarse e incluso herniarse con las complicaciones consecuentes

El máximo exponente del traumatismo cardíaco cerrado es la rotura cardíaca (Rogers FB, Leavitt BJ. "Upper Torso Cyanosis: a marker for blunt cardiac rupture”, Am J Emerg Med 1997; 15: 275-276), bien sea de la pared libre, el septo interventricular, los músculos papilares o las cuerdas tendinosas.

La rotura de la pared libre es la manifestación más frecuente del traumatismo cardíaco, pero su diagnóstico en la mayoría de las ocasiones se realiza durante la necropsia. La rotura traumática del septo interventricular es menos frecuente. La disfunción traumática del aparato subvalvular mitral origina insuficiencia de dicha válvula en mayor o menor grado, dependiendo de si la rotura se circunscribe a una sola cuerda o es más extensa. Más frecuente es la afectación de la válvula aórtica, que en la mayoría de las ocasiones se asocia a una lesión traumática de la aorta ascendente, que puede ser debida a disección o rotura.

La localización más habitual de la rotura traumática de la aorta se circunscribe al istmo aórtico, justo por debajo del origen de la arteria subclavia izquierda. Sólo ocasionalmente se observan lesiones múltiples ocasionadas por diferentes mecanismos en el mismo traumatismo torácico.

Otra lesión con compromiso vital potencial es el volet costal, que se produce por la fractura en doble foco de varias costillas consecutivas en el mismo hemitórax, lo que origina una porción en la pared torácica "flotante", que oscila con la respiración de un modo inverso (se deprime en inspiración y protuye en espiración).es lo que se llama "movimiento paradójico". clínicamente aparece inestabilidad de una zona del tórax y una insuficiencia respiratoria de grado variable (depende del dolor producido por las fracturas costales, de la probable contusión pulmonar subyacente y del grado de desestructuración del tórax).

Swank. G. y cols., "Lesión torácica por deceleración”, J. Trauma, 2001, Vol. 51: 970-974, refieren que entre las cinco lesiones principales torácicas por deceleración (contusión miocárdica, rotura traumática de aorta, fractura esternal, volet torácico y rotura traqueo-bronquial), las lesiones coexistentes son llamativamente raras.

Los autores revisaron las historias clínicas de todos los pacientes con diagnósticos finales de las lesiones mencionadas anteriormente tratadas en el Centro Médico de la Universidad de New Jersey en Newark, en los diez años precedentes a 1997.

Entre 142 pacientes, todas víctimas de accidentes de tráfico hubo 38 contusiones miocárdicas, 36 roturas traumáticas de aorta, 33 fracturas esternales, 28 volets torácicos y 7 roturas traqueobronquiales. Hubo seis lesiones coexistentes $(3,5 \%)$. 
Las lesiones torácicas por deceleración se producen cuando un individuo se mueve hacia delante y se detiene repentinamente, golpeando con alguna parte del tórax con algún obstáculo que está fijo o se mueve a una velocidad mucho menor.

Los accidentes de tráfico son la causa más frecuente y los ocupantes de los asientos delanteros son los más vulnerables. Las caídas desde altura son otras causas de ese tipo de lesiones.

Las lesiones principales a menudo con riesgo vital, incluyen rotura traumática de aorta, rotura traqueo-bronquial, contusión miocárdica, fractura esternal y volet torácico. Algo sorprendente es la observación de que raramente se ven cualquiera de estas lesiones combinadas en el mismo paciente.

Por ejemplo un choque frontal entre automóviles y conductores comparables, produce una fractura esternal sufrida por un conductor y una rotura traumática de aorta por el otro.

Los autores mantienen la hipótesis de que esas lesiones torácicas por deceleración, pueden producirse por combinación y que los pacientes con ellas raramente llegan vivos al hospital y que si lo hacen, el pronóstico es sombrío.

La observación infrecuente de lesiones asociadas, puede deberse a que dichas lesiones no se reconocen, debido a que la víctima muere en la zona del accidente o poco tiempo después de la llegada al hospital, y no se realiza la autopsia. Si se observan lesiones coexistentes, el pronóstico es malo, ya que en este estudio se observó una mortalidad del 67\%. Si existía asociación de tres lesiones torácicas por deceleración, el pronóstico era incluso peor, mostrando una mortalidad del $100 \%$.

La incidencia de contusión miocárdica es difícil de valorar, por la simple razón de que el diagnóstico es a menudo impreciso. Han existido diversos criterios, tales como presencia de arritmias que requieren tratamiento farmacológico, otros criterios tales como mecanismo lesivo, elevación enzimática, trastorno de contractilidad en el ecocardiograma, etc.

Bertinchant y cols. (J. Trauma, 2000; 48:924-931), refieren que "la incidencia referida de contusión miocárdica tras trauma torácico cerrado, varía entre el $0 \%$ y el $76 \%$ de pacientes, dependiendo de los criterios utilizados para establecer el diagnóstico".

En su estudio de 94 pacientes, la contusión miocárdica se diagnosticó en el 28\% y el diagnóstico se basó en hallazgos significativos, electrocardiográficos o ecocardiográficos. El 31\% de pacientes tenían fractura esternal y el 39\% volet torácico.

De interés es que la incidencia de fractura esternal entre los 68 pacientes con sospecha de tener, pero en quienes no se encontró que hubieran sufrido contusión miocárdica, no fue significativamente diferente (36\%) de los pacientes en quienes se confirmó contusión miocárdica (31\%). 
La incidencia de contusión miocárdica es difícil de valorar, por la simple razón de que el diagnóstico es a menudo impreciso. Han existido diversos criterios, tales como presencia de arritmias que requieren tratamiento farmacológico, otros criterios tales como mecanismo lesivo, elevación enzimática, trastorno de contractilidad en el ecocardiograma, etc.

Patetsios P. y cols. "Lacerations of the Left Ventricle from Rib Fractures alter Blunt Trauma”, J. Trauma, Vol. 49, Oct. 2000, pág. 771-773, refieren que el traumatismo cerrado de tórax puede producir una serie de diferentes lesiones cardiacas en función de diferentes mecanismos. La lesión más frecuente incluye rotura cardiaca, insuficiencia valvular y rotura de cava inferior auricular. Incluso estas lesiones son relativamente raras.

En una revisión retrospectiva de 10 años de todos los pacientes con traumatismo ingresados en su centro, Perchinsky y cols., "Blunt Cardiac Rupture", Arch. Surg. 1995; 130:852-857, refirieron solamente 27 pacientes con lesión cardiaca cerrada (el $0,16 \%$ de todos los pacientes con traumatismo cerrado).

La incidencia de lesión cardiaca producida por punción directa desde una costilla fracturada es todavía más rara. En su serie de 27 pacientes Perchinsky y cols., refirieron solo un paciente al que atribuyeron el desgarro cardiaco a la punción por una costilla fracturada.

Una revisión de la literatura mundial realizada en el año 2000, revelaba cinco casos referidos de lesiones penetrantes cardiacas directamente atribuibles a fracturas costales en los que la evolución del paciente estaba bien definida.

Así, Glock y cols. "Cardiac Damage in Nonpenetrating Chest Injuries", J. Cardiovasc. Surg. 1989: 30:27-33; Suszko B. "Heart Injury Caused by a Rib Fragment", Pol Tyg Lek, 1968; 23:595; Glock y cols. "Left Ventricular Perforation by a Rib Fracture Following Closed Thoracic Trauma", Ann. Chir. Thorac. Cardiovasc. 1986;40:98-101; Bourguignon y cols. "Heart Injury Following Closed Thoracic Injury", Ann. F. Anesth. Reanim. 1996; 15:1088-1089; Galvin y cols. "Fractured Rib with Penetrating Cardiopulmonary Injury", Surg. 1993; 56:558-559, refieren ese tipo de lesión.

Fulda G. y cols. "Blunt Traumatic Rupture of the Heart and Pericardium: A Ten-year Experience (1979-1989)”, J. Trauma, Vol. 31, No. 2, Feb. 1991, pág. 167-173, en una revisión de más de 20.000 pacientes ingresados en un centro de trauma de nivel 1 identificaron 59 pacientes que precisaron cirugía de urgencia por esta causa.

Observaron que el 63\% de los pacientes (37) tenían rotura aislada de una cámara cardiaca, el 29\% (17 pacientes) tenían rotura pericárdica aislada y solamente el $8 \%$ (5 pacientes) tenían rotura combinada de pericardio y de una cámara cardiaca. Un total de 18 pacientes $(30,5 \%)$ tenían rotura ventricular, estando afectado el lado derecho en 12 pacientes (67\%) y el 22\% tenían desgarro ventricular derecho (4 pacientes). Dos pacientes (11\%) sufrieron roturas 
biventriculares. De los que tuvieron desgarro auricular (26 pacientes -un 44\% del total-), tenían desgarro de aurícula derecha 17 siendo la más frecuente.

En esta serie, un total de 35 pacientes tenían una historia documentada suficientemente para valorar lesiones asociadas, y de los 35, 17 (un 51\%) tenían algún tipo de lesión en la cabeza, de ellos 13 con traumatismo cráneoencefálico cerrado, 6 con fracturas faciales múltiples y 3 con fractura de cráneo. Las lesiones torácicas fueron muy frecuentes sufriendo fracturas costales múltiples. Se encontraron lesiones abdominales en 15 pacientes (el 43\%) siendo la lesión en hígado la más frecuente observándose en 8 pacientes. Sufrieron traumatismo de miembros 14 pacientes (un 40\%) de ellos 7 con fracturas en miembros inferiores y 3 con fracturas en miembros superiores.

Se han postulado siete mecanismos de rotura cardiaca en el traumatismo cerrado:

1. Impacto directo en la zona precordial

2. Efecto hidráulico, que se produce cuando una fuerza intensa se dirige al abdomen y miembros inferiores. La fuerza se trasmite a través del abdomen hacia el sistema venoso. Una elevación muy brusca y muy intensa de la presión venosa se trasmite al corazón, especialmente a la aurícula. Estos pacientes pueden tener rotura auricular y posiblemente ventricular, sin evidencia de traumatismo directo en pared torácica.

3. Compresión. El corazón resulta atrapado entre el esternón y la columna vertebral.

4. Lesiones por aceleración y desaceleración. Debido a la diferencia entre la movilidad del corazón y la de sus fijaciones, una desaceleración rápida puede llevar a desgarros del corazón y sus fijaciones a los vasos fijos. Este es probablemente el mecanismo de las lesiones aurículo-cava.

5. Lesión "por onda explosiva” -Blast-. La tremenda presión generada por la fuerza de la onda explosiva dirigida al tórax puede romper las cámaras cardiacas.

6. Golpe contusivo. La contusión cardiaca se ha considerado mortal a través de la producción de arritmias malignas. Puede producirse rotura cardiaca tardía secundaria a necrosis miocárdica tras la contusión referida.

7. Trauma penetrante secundario. Fragmentos de costillas o esternón fracturado por el traumatismo cerrado tienen la posibilidad de penetrar en una cámara cardiaca.

Getz y cols., "Blunt Cardiac Trauma Resulting in Right Atrial Rupture”, J.A.M.A., 255: 761-763, 1986, sugirieron que el factor determinante entre la rotura ventricular frente a la auricular depende de la fase del ciclo cardiaco en el cual se produzca el incremento brusco de la presión cardiaca. Por lo tanto, la rotura ventricular es más probable que se produzca hacia el final de 
la diástole y la rotura auricular que se produzca en la sístole tardía cuando todas las válvulas están cerradas.

Respecto a la rotura traumática de pericardio, según un artículo clásico, Borrie J. y Lichter I. ("Pericardial rupture from blunt chest trauma", Thorax, 1974, Vol. 29, pág. 329-337), la rotura puede producirse en dos zonas anatómicas: pericardio diafragmático y pleuropericardio. En el primer caso, la rotura puede afectar a la cavidad pericárdica sola o puede extenderse a una o a ambas cavidades pleurales adyacentes. Se puede sospechar por la existencia de un neumoperitoneo, y puede haber herniación de vísceras intraabdominales. A veces se diagnostica sólo tras toracotomía, cuando no se extiende a la cavidad pleural.

En la rotura pleuropericárdica, el desgarro generalmente es vertical y con mayor frecuencia en el lado izquierdo. Se sospecha por la presencia de aire intrapericárdico que procede del traumatismo pulmonar asociado. Puede producirse salida del corazón del saco pericárdico, a una cavidad pleural, con constricción o estrangulación cardíaca.

Así, Janson J. T. y cols. "Pericardial Rupture and Cardiac Herniation Alter Blunt Chest Trauma”, Ann. Thorac. Surg., 2003; 75:581-2, Levine A. J. "Blunt traumatic pericardial rupture", J. Accident and Emerg. Med., 1995, 12: 55-56, y Sohn J. H. y cols "Pericardial rupture and cardiac herniation alter blunt trauma: a case diagnosed using cardiac MRI", refieren casos de herniación cardíaca secundaria a rotura de pericardio. Estos últimos, han observado que un $64 \%$ de los casos se asociaban a herniación cardíaca. Se puede producir rotura combinada de pared libre del miocardio y rotura pericárdica, con hemotórax,

Clark D. E y cols "Traumatic rupture of the pericardium”, Surgery, 1983, 93:495-503, en una revisión de la literatura, describían 142 casos de rotura traumática de pericardio. El pleuropericardio izquierdo estaba lesionado en 71 casos (50\%), el derecho en 24(17\%), el pericardio diafragmático en 39 casos (27\%) y el pericardio mediastínico superior en 6 casos (4\%). Se encontró herniación cardíaca en 31 y 5 de ls defectos pleuropericárdicos izquierdo y derecho, respectivamente, y en 4 desgarros de pericardio diafragmático.

En la rotura pleuropericárdica, el desgarro con mayor frecuencia se localiza a nivel del nervio frénico, y si la rotura es suficientemente grande, se puede producir la herniación cardíaca.

Fulda G. y cols., "Blunt traumatic ruptura of the heart and pericardium: A ten-year experience (1979-1989)”, J. Trauma, 1991: 31: 167-72. describen una incidencia de un $8 \%$ de rotura pericárdica asociada a rotura cardíaca, con una frecuencia de 20 casos entre 20.000 pacientes ingresados en un Centro de Trauma.

Se ha descrito la rotura pericárdica como lesión en ocupantes de automóvil que usaban cinturón de seguridad, Benckert C. y cols, "Harm from Seat belt: 
Transthoracic lung herniation and pericardial rupture", J. Thor. and Cardiov. Surg., Feb. 2007, 133: 588-9, sobre todo en automóviles no provistos de airbag, como lesión asociada a fractura de esternón, fracturas costales, etc.

La rotura pericárdica traumática es una lesión poco frecuente, asociada a una mortalidad elevada. Fue descrita por primera vez por Morel-Lavallé en 1864, ("Rupture du pericarde: bruit de roue hydraulique, bruit de muoulin", Gaz. Med. Paris, 1864:19, 695-696, 729-30, 771-2, 803-8) y se encuentra en alrededor del 3\% de pacientes estudiados en autopsia, y en tres estudios se describía una mortalidad de hasta 63\%.

Su mecanismo es similar al de la rotura de aorta, es decir una lesión por desaceleración, y un traumatismo de suficiente intensidad como para producir rotura de pericardio, a menudo supone una lesión mortal, ya que es precisa una gran fuerza para romper el pericardio. El mecanismo de una tensión de estiramiento y tracción asociadaza lesiones por aceleración-desaceleración se ha considerado un mecanismo de rotura traumática de aorta, que a menudo se asocia a la rotura pericárdica. Se ha descrito asociado a insuficiencia valvular tricuspídea, tras trauma cerrado de tórax. Se han descrito supervivencias del $36,4 \%$ al $42,9 \%$ entre los pacientes que llegan vivos al hospital y a los que se les diagnostica la rotura de pericardio.

El traumatismo torácico es responsable de aproximadamente el 25\% de las muertes por traumatismo cerrado, y las lesiones de la porción intrapericárdica de los grandes vasos suponen una parte muy pequeña de esas muertes. Así, la rotura intrapericárdica de grandes vasos es una lesión rara y generalmente mortal, y la mayoría de pacientes fallecen antes de llegar al hospital (Clemens R. H., Fisher P. J. "Blunt Injury of the Intrapericardial Great Vessels”, J. Trauma, 2001; 50:129-132),

Se han propuesto varios mecanismos como causa de estas lesiones. La vena cava inferior (VCI) está fija cuando atraviesa el diafragma. Una desaceleración rápida mueve el corazón, móvil, hacia delante, y desgarra la VCI en su punto de fijación al diafragma. La vena cava superior (VCS), asimismo está fija al pericardio, haciéndola vulnerable a las fuerzas de tracción y desgarro. Se ha propuesto una deceleración hacia abajo del hígado, que tiende a romper la vena cava en el pericardio. El efecto Valsalva y el empuje de la sangre desde la compresión del tórax y la compresión abdominal, pueden romper cualquiera de los grandes vasos en el momento del impacto.

Respecto a la rotura bronquial y de venas pulmonares, Le Guyader A., Fertin F. y cols. "Case report: Blunt Chest Trauma: a right pulmonary vein rupture”, Eur. J. of Cardio-Thoracic Surg. 20 (2001) 1054-1056, refieren que la rotura traumática de venas pulmonares y la lesión aislada de esta vena es infrecuente. Puede asociarse a lesión de aurícula izquierda, a desgarro de aurícula derecha y también se ha descrito rotura por traumatismo cerrado de los vasos 
pulmonares principales de ambos pulmones (Hanline NH. "Blunt traumatic rupture of the main pulmonary vessels", South Med J 1983;76(4):541-542).

El traumatismo torácico cerrado puede llevar a desgarro aislado o múltiple o a rotura de estructuras intratorácicas: cámara cardiaca, que es la lesión visceral observada con mayor frecuencia pero la más frecuentemente no sospechada, responsable de muerte en víctimas de accidentes, grandes vasos, vía aérea, arteria y venas pulmonares (Bratwaite DE, Rodríguez A, Turney SZ, Dunham CM, Cowley R. "Blunt traumatic cardiac rupture: a 5-year experience", Ann Surg 1990; 212(6):701-704).

Los vasos pulmonares rotos pueden drenas en la cavidad pleural produciendo un hemotórax o en el pericardio con o sin taponamiento en función de la ausencia o existencia de un desgarro pericárdico.

Se ha propuesto varios mecanismos para explicar esta lesión: efectos de desaceleración sobre estructuras no fijas del tórax; compresión bidireccional entre el esternón y los cuerpos vertebrales; fuerza indirecta desde el abdomen que aumenta la presión intratorácica y produce rotura, y fuerzas por onda explosiva (blast).

Weltman D. I. y cols. "Case Report: CT Diagnosis of Laceration of the Main Pulmonary Artery After Blunt Trauma”, AJR 173. Noviembre 1998, pág. 1361-1363, refieren que la supervivencia de pacientes tras desgarro de arteria pulmonar principal por trauma cerrado es extremadamente rara y los autores utilizaron TAC con contraste para el diagnostico preoperatorio de lesión de arteria pulmonar que a veces puede ser difícil de diferenciar de la lesión de aorta torácica.

Daon E. y Gorton M.E., “Traumatic Disruption of the Innominate and Right Pulmonary Arteries: Case Report”, J. Trauma, Vol. 43(4), Oct. 1997, pág. 701-702, refieren un caso de lesión proximal de tronco braquiocefálico y de arteria pulmonar intrapericárdica por traumatismo cerrado. En general las lesiones de grandes vasos son raras suponiendo menos del 5\% de todos los traumatismos vasculares en ámbito civil. La verdadera incidencia de la lesión vascular mediastínica es probablemente mayor de lo indicado ya que estos pacientes es menos probable que sobrevivan suficiente tiempo como para ser evaluados y diagnosticados.

El diagnóstico se basa en la historia (lesión por desaceleración, caída desde altura) y la exploración física (volet torácico, signos de impronta del volante o del cinturón de seguridad sobre el tórax) así como un alto índice de sospecha. Entre los signos radiológicos sugerentes de lesión de grandes vasos se incluyen el ensanchamiento mediastínico, fractura de la primera y segunda costillas, fractura de escápula o casquete pleural.

Hawkins ML, Carrway RP y cols. "Pulmonary Artery Disruption from Blunt Thoracic Trauma”, The Am. Surgeon, March 1988, Vol. 54, No. 3, pág. 
149-152, refieren que el traumatismo torácico cerrado está presente en el 35 al 50\% de todos los accidentes de tráfico mortales. De los pacientes con traumatismo torácico que llegan vivos a urgencias, solo el 10-15\% precisan toracotomía precoz.

El desgarro de arteria pulmonar por traumatismo cerrado se produce infrecuentemente. Kemmerer y cols. (Kemmerer WT, Eckert WG, Gathwright JB, Reemtsma K, Creech O. "Patterns of thoracic injuries in fatal traffic accidents", J Trauma 1961; 1:595-599), analizaron los resultados de autopsia de 585 víctimas de accidentes de tráfico. De estos pacientes se pensó que 133 habían muerto principalmente por traumatismo torácico incluyendo 4 pacientes que tenían un desgarro de arteria pulmonar.

El Filky M. ("Traumatic closed complete and partial rupture of the main bronchi accompanied with closed rupture of main pulmonary artery, a critical analysis and review of the literature", J. Egypt Med Assoc 1977; 60:243-255) refirió 10 casos de rotura bronquial traumática, uno de los cuales también tenían un desgarro de arteria pulmonar.

Blair E., Topuzly C. y Davis NH ("Delayed or missed diagnosis in Blunt Chest Trauma”, J Trauma 1971; 11:129-145) refirieron 90 pacientes con traumatismo torácico cerrado grave que tuvieron diagnósticos diferidos o erróneos. Un paciente tenía un desgarro de la arteria pulmonar principal.

El desgarro cerrado de venas pulmonares es mucho menos probable que ocurra que el de arteria pulmonar y clínicamente puede manifestarse por una presión extremadamente baja en estos vasos.

Ambrose G., Barrett L. O. y cols. "Main Pulmonary Artery Laceration After Blunt Trauma: Accurate Preoperative Diagnosis”, Ann Thorac Sug 2000; 70, 955-957, refieren que la localización más frecuente de la lesión cerrada de estructuras intratorácicas es el hilio y los pacientes generalmente presentan hemotórax.

La lesión de arteria pulmonar puede clasificarse como intrapericárdica o extrapericárdica. Las lesiones intrapericárdicas se presentan con taponamiento y a menudo pueden ser reparadas sin bypass cardiopulmonar.

McKeown P. P., Rosemurgy A. y Conant P., "Blunt Traumatic Rupture of Pulmonary Vein, Left Atrium and Bronchus”, Ann Thorac Surg. 1991; 52: 1171-1172, refieren que la lesión de corazón, grandes vasos y estructuras traqueobronquiales por trauma cerrado puede no ser sospechada clínicamente pero se produce en el 10 al 15\% de los accidentes mortales (Getz BS, Davies E, Steinberg SM, Beaver BL, Koenig FA. "Blunt cardiac trauma resulting in right atrial rupture”, JAMA 1986; 255:761-763 - Bertelsen S, Howitz P. "Injuries of the trachea and bronchi", Thorax 1972; 27: 188-194).

Los accidentes de tráfico son la causa más frecuente de traumatismo torácico cerrado. La lesión grave de estructuras intratorácicas puede producirse 
en ausencia de fracturas y, en síntesis y como se ha comentado anteriormente, puede ser atribuida a varios mecanismos:

1. una fuerza indirecta o impulso hidráulico" desde el abdomen y las extremidades inferiores que aumenta la presión intratorácica y produce rotura sin un golpe directo al pecho;

2. compresión bidireccional entre el esternón y los cuerpos vertebrales;

3. efecto de aceleración/desaceleración sobre las estructuras fijas del tórax; y

4. fuerzas de estallido (blast). Las estructuras intratorácicas también pueden ser dañadas por una fractura costal o esternal; sin embargo las fracturas óseas del tórax no necesariamente anuncian lesiones graves y así un subtipo de pacientes tiene lesiones intratorácicas graves sin fracturas costales.

Varghese D., Patel H. y cols. "Repair of Pulmonary Vein Rutpture After Deceleration Injury”, Ann Thorac Surg 2000; 70: 656-658, refieren que la lesión aislada de vena pulmonar como causa de un hemotórax masivo es extremadamente rara y se ha teorizado que tras la rotura de una vena pulmonar y desarrollo subsiguiente de un hemotórax a baja presión, la cavidad pleural forma parte de este sistema de baja presión y funciona efectivamente como una aurícula izquierda gigante.

Por tanto, la retención de sangre en la cavidad pleural permite el mantenimiento de la hemodinámica (como durante el clamplaje de un drenaje torácico) mientras que la liberación de sangre desde el hemotórax produce una depleción rápida de volumen.

Respecto a las roturas cardíacas internas como consecuencia de traumatismos cerrados de tórax, secundarios a accidentes de tráfico, se han descrito lesiones valvulares agudas, que pueden afectar tanto a los velos como a cuerdas tendinosas, músculos papilares (Simmers T. A, Meijburg Huub W. J,, Brutel de la Riviére A., "Traumatic papillary muscle rupture”, The Annals of Thoracic Surgery, 2001, vol. 72, nº1, pp. 257-259.

La rotura de músculo papilar producida por traumatismo torácico cerrado es una causa poco frecuente de insuficiencia mitral. Hasta 2001 se habían referido sólo 25 casos de insuficiencia mitral postraumatica corregida quirúrgicamente, de las cuales sólo ocho se debían a rotura del músculo papilar anterolateral.

Con posterioridad se han descrito nuevos casos (Cordovil A, Fischer $\mathrm{CH}$, Rodrigues AC, Lira Filho EB, Vieira ML, Cury AF, Naccarato GA, Valente C, Brandão CM, Pommerantzeff PM, Morhy SS, "Papillary muscle rupture after blunt chest trauma,” J. Am. Soc. Echocardiogr. 2006 Apr; 19(4):469.e1-3), con diagnóstico mediante ecocardiografía transesogáfica.

Se ha referido que los mecanismos de la lesión papilar incluyen compresión del corazón durante la telediástole o en la fase de contracción isovolumétrica, 
cuando las válvulas están a punto de cerrarse o se acaban de cerrar. Una compresión torácica intensa aumenta la presión intracardíaca y conduce a un prolapso grave de la válvula y a rotura. La gravedad del traumatismo cardíaco no siempre se relaciona con la gravedad del traumatismo, y, por otra parte, la aparición de insuficiencia cardíaca secundaria a la lesión valvular puede aparecer inmediatamente a la lesión o retasarse horas, días e incluso años. Se pueden producir también úlceras en los velos valvulares, etc., así como afectaciones de tabique.

La lesión valvular mas frecuente es la de válvula aórtica, seguida de válvula mitral y tricuspíde. Se han descrito también lesiones asociadas de mas de una válvula, o lesiones valvulares junto a otras lesiones cardíacas (Cuadros CL, Hutchinson JE 3rd, Mogtader AH., "Laceration of a mitral papillary muscle and the aortic root as a result of blunt trauma to the chest. Case report and review of the literature”, J Thorac Cardiovasc Surg. 1984 Jul; 88(1):134-40.

La insuficiencia tricúspide traumática es una rara complicación del traumatismo torácico cerrado, aunque se ha referido con frecuencia creciente en los últimos 45 años, debido especialmente a los accidentes de tráfico. La lesión mas frecuente es. la rotura de cuerdas, seguida de la rotura del músculo papilar anterior y del desgarro del velo, principalmente del velo anterior, pudiendo pasar desapercibida la lesión en la fase aguda; en la fase crónica pueden faltar síntomas o aparecer síntomas y signos de insuficiencia cardíaca; cuando hay fallo cardíaco derecho franco, está indicada la cirugía, aunque recientemente se tiende a operar mas precozmente, sin esperar la aparición de signos de insuficiencia cardíaca. (Dounis G, Matsakas E, Poularas J, Papakonstantinou K, Kalogeromitros A, Karabinis A, “Traumatic tricuspid insufficiency: a case report with a review of the literature”, Eur J Emerg Med. 2002 Sep;9(3):258-61)..

También se han descrito lesiones de arterias coronarias, con producción consiguiente de infarto agudo de miocardio, incluso afectando simultáneamente a dos vasos (Lai, Chao-Hung Ma, Tsochiang, Chang, Ting-Chuan ; Chang, Mu-Hsin ; Chou, Pesus ; Jong, Gwo-Ping,; "A case of blunt chest trauma induced acute myocardial infarction involving two vessels", Int Heart J., 2006-Jul; Vol 47 No 4, pp 639-43), o produciendo taponamiento cardíaco diferido (Bozinovski J, Wang S, Nakai S. "Delayed cardiac tamponade after coronary artery laceration”, Ann Thorac Surg 2002; 73(4): 1314-5 -Review). 
Resumo: Lesão por desaceleração após colisão frontal

Relata-se um acidente de viação, resultante de uma colisão frontal muito violenta entre um transporte de pesados e um automóvel, de que resultou a morte imediata dos quatro jovens ocupantes do automóvel.

Analisa-se especificamente a lesão torácica por desaceleração apresentada por todas as vítimas, com lesões dos grandes vasos, cardíacas, etc, que constituíram a causa de morte, bem como outras lesões associadas que incluíam traumatismo craneo-encefálico e traumatismo abdominal com rotura de víscera maciça e ainda traumatismo dos membros.

Palavras-chave: Biomecânica; lesão por desaceleração; rotura dos grandes vasos; rotura cardíaca; traumatismo torácico fechado; colisão frontal.

Summary: Deceleration injury alter head-on collision

A very violent head-on (frontal) crash between a truck and a car, resulting in immediate death of the four young male occupants of the car is reported.

Specific comments are made on thoracic deceleration injury, suffered by the four occupants who presented great vessels and cardiac injuries, causing their death, associated to other injuries including severe head and abdominal trauma with solid organ rupture, as so orthopaedic trauma located in upper and lower limbs.

Key-words: Biomechanics; deceleration injury; great vessels rupture; cardiac rupture; blunt chest trauma; head-on (frontal) collision.

Résumé: Lésion par décélération après collision frontale L'auteur rapporte un accident de trafic consistant dans une collision frontale entre un camion et un automobile, avec une grande violence, dont le résultat a été la mort «in situ» des quatre jeunes occupants de l'automobile.

Est commentée d'une manière spécifique la lésion thoracique par décélération qui était présentée par les quatre occupants, avec des lésions des grands vaisseaux, des lésions cardiaques, etc.., qui ont été la cause de la mort, ainsi que d'autres lésions associées - un traumatisme crânien et un traumatisme abdominal avec rupture de viscère massive et encore un trauma orthopédique aux membres supérieurs et inférieurs.

Mots-clés: Biomécanique; lésion thoracique par décélération; rupture des grands vaisseaux; rupture cardiaque; traumatisme thoracique fermé; collision frontale.

Pedido de separatas:

ANTÓNIO HERNANDO LORENZO

herloren@telefonica.net 